\title{
Basal Cell Carcinoma Arising on a Verrucous Epidermal Nevus: A Case Report
}

\author{
Analia Viana $^{a}$ Felipe Aguinaga $^{a} \quad$ Flauberto Marinho $^{a}$ \\ Rosangela Rodrigues $^{a}$ Tullia Cuzzi ${ }^{b}$ Marcia Ramos-e-Silva ${ }^{a}$ \\ ${ }^{a}$ Sector of Dermatology and Post-Graduation Course and ${ }^{b}$ Sector of Pathology, \\ University Hospital and School of Medicine, Federal University of Rio de Janeiro, \\ Rio de Janeiro, Brazil
}

\section{Key Words}

Basal cell carcinoma Epidermal verrucous nevus

\begin{abstract}
We report a case of basal cell carcinoma that appeared from an epidermal verrucous nevus in a 61-year-old patient. The onset of basal cell carcinoma in sebaceous nevi, basal cell nevi and dysplastic nevi is relatively common, but it is rarely associated with epidermal verrucous nevi. There is no consensus on whether the two lesions have a common cellular origin or whether they merely represent a collision of two distinct tumors. Since this association - as with other malignant tumors - is rare, there is no need for prophylactic removal of epidermal verrucous nevi.

(C) 2015 S. Karger AG, Basel
\end{abstract}

\section{Introduction}

Epidermal verrucous nevi are congenital cutaneous hamartomas composed of keratinocytes. Their prevalence in adults ranges from 0.1 to $0.5 \%$ and they are usually present at birth. Malignant transformation is often observed in sebaceous nevi, basal cell nevi and dysplastic nevi, while it is rare in verrucous epidermal nevi.

We report the case of a 61-year-old patient with a basal cell carcinoma (BCC) arising on a linear verrucous epidermal nevus. There is no consensus on whether the two lesions have a common cellular origin or whether they merely represent a collision of two distinct tumors. 
Viana et al.: Basal Cell Carcinoma Arising on a Verrucous Epidermal Nevus: A Case Report

\section{Case Report}

A 61-year-old man came to our dermatology outpatient clinic reporting modification of the aspect of a lesion on his back, which had been present since birth. At examination, a dark-brown pearly shiny papule $0.5 \mathrm{~cm}$ in diameter was observed on a linear brownish verrucous lesion of about $12 \mathrm{~cm}$ in the interscapular region (fig. 1). Dermoscopy evidenced a cerebriform pattern with follicular pseudo-openings and a large ovoid nest with arboriform vessels (fig. 2). The diagnostic hypothesis was BCC appearing from a localized verrucous epidermal nevus. The patient was subsequently submitted to excisional biopsy of the lesion on the same day. Histopathological examination evidenced papillomatous and acanthotic epidermis in different segments and in the free upper dermis, not occupied by adnexal structures, eliminating the diagnosis of organoid nevus (sebaceous), and compatible with verrucous epidermal nevus. A thin epidermis on the dermal lesion represented by groupings of basaloid cells with a peripheral nuclear palisade, compatible with BCC, was also observed (fig. 3, fig. 4). The patient was followed up and after 18 months did not present signs of recurrence of the BCC or appearance of other cutaneous neoplasia.

\section{Discussion}

Verrucous epidermal nevi are cutaneous congenital hamartomas composed of keratinocytes. Their prevalence in adults ranges from 0.1 to $0.5 \%$ [1]. Commonly present at birth, they may also appear later during childhood and rarely in adolescence. Clinically they present as brownish verrucous papules, which may coalesce forming papillomatous plaques, almost always in a linear configuration, sometimes following the Blaschko lines. Sometimes the nevi present growth during childhood, stabilizing in puberty [1].

Malignant transformation is well reported for sebaceous, basal cell and dysplastic nevi, while it is rare in verrucous epidermal nevi. There are about 13 reports of squamous cell carcinoma [2, 3] and isolated cases of Bowen's disease [4], keratoacanthoma [5], apocrine multifocal papillary adenoma [6] and malignant eccrine poroma [7] arising from verrucous epidermal nevi. There are very few reports describing BCC appearing on verrucous epidermal nevi [8-14].

Adamson [15], in 1914, suggested that BCC was a nevoid tumor originating from a focus of latent embryonic cells activated later in time. He believed that this focus would be composed of embryonic pilosebaceous follicles and, occasionally, of embryonic sweat ducts. Pinkus [16], in 1953, suggested that BCC, when occurring in adult age, did not originate from quiescent embryonic cells of the primary epithelial germ, but from pluripotent cells that form continuously during life. These, like the cells from the primary epithelial germ, would have the potential to form hairs, sebaceous and apocrine glands. As epidermal nevi also originate from pluripotent cells of the basal layer of the embryonic epidermis, this could provide an explanation for the appearance of BCC in areas of epidermal nevi.

In 2009, Hafner et al. [9] investigated whether BCC appearing on an epidermal nevus was directly derived from the cells of the epidermal nevus and therefore clonally related, or whether it only represented a collision of independent tumors. The mosaicisms of FGFR3 and PIK3CA mutation were studied, already established in the pathogenesis of non-organoid nevi, known for holding oncogenic potential and for being found in several malignant tumors, through genetic analysis of biopsy fragments. The analysis favored the hypothesis of distinct clonal origin between the two lesions; however, it was not possible to completely exclude a clonal relation because the BCC would appear at a different moment than the ver- 
Viana et al.: Basal Cell Carcinoma Arising on a Verrucous Epidermal Nevus: A Case Report

rucous epidermal nevus. We also emphasize that the lesions could share a still unknown genetic molecular alteration.

The risk for development of BCC in sebaceous nevi ranges from 6.5 to 50\% [17], which justifies the recommendation of its prophylactic excision by many authors. Comparing the high prevalence of verrucous epidermal nevi in the general population $(1: 1,000)$ with the few reported cases of association with BCC, and even of other malignant neoplasia, it is not reasonable to state that lesions of verrucous epidermal nevi hold an increased risk of malignant transformation.

\section{Conclusion}

Since the association is very uncommon and it seems, at least until now, that verrucous epidermal nevi do not evolve into malignant tumors, the prophylactic removal of all verrucous epidermal nevi is not recommended, contrary to sebaceous nevi.

\section{Disclosure Statement}

The authors have no conflict of interest for this publication.

\section{References}

1 Thomas VD, Swanson NA, Lee KK: Benign epithelial tumors, hamartomas and hyperplasias; in Wolff K, Goldsmith LA, Katz SI, Gilchrest BA, Paller AS, Leffell DJ (eds): Fitzpatrick's Dermatology in General Medicine, ed 7. New York, McGraw-Hill, 2008, pp 1054-1067.

-2 Toya M, Endo Y, Fujisawa A, Tanioka M, Yoshikawa Y, Tachibana T, Miyachi Y: A metastasizing squamous cell carcinoma arising in a solitary epidermal nevus. Case Rep Dermatol Med 2012;2012:109632.

-3 Riad H, Mansour K, Al Sada H, Al Naama K, Al Shaigy A, Hussain K: Fatal metastatic cutaneous squamous cell carcinoma evolving from a localized verrucous epidermal nevus. Case Rep Dermatol 2013;5:272-282.

4 Swint RB, Klaus SN: Malignant degeneration of an epithelial nevus. Arch Dermatol 1970;101:56-58.

5 Rosen TJ: Keratoacanthomas arising within a linear epidermal nevus. Dermatol Surg Oncol 1982;8:878-880.

-6 Rechdouni A, Urata MM, Saadat P, Vadmal MS: Multifocal papillary apocrine adenoma arising in a systematized linear epidermal nevus. Cutis 2004;73:348-352.

7 Hamanaka S, Otsuka F: Multiple malignant eccrine poroma and a linear epidermal nevus. J Dermatol 1996;23:469-471.

-8 Zheng LQ, Huang Y, Qu YJ, Zhang YH, Han XC: Multiple basal cell carcinomas arising in a verrucous epidermal nevus. J Dermatol 2013;40:482-483.

-9 Hafner C, Klein A, Landthaler M, Vogt T: Clonality of basal cell carcinoma arising in an epidermal nevus. New insights provided by molecular analysis. Dermatology 2009;218:278-281.

10 Ceylan C, Ozdemir F, Oztürk G, Akalin T: A case of basal cell carcinoma arising in epidermal nevus. Int J Dermatol 2002;41:926-927.

11 De D, Kanwar AJ, Radotra BD: Basal cell carcinoma developing in verrucous epidermal nevus. Indian J Dermatol Venereol Leprol 2007;73:127-128.

12 Horn MS, Sausker WF, Pierson DL: Basal cell epithelioma arising in a linear epidermal nevus. Arch Dermatol 1981;117:247.

13 Taki T, Izawa Y, Usuda T, Kozuka S, Tsubone M, Hoshino M, Aoki J: Basal cell epithelioma occurring in an epidermal nevus. Acta Pathol Jpn 1984;34:859-862.

14 Goldberg HS: Basal cell epitheliomas developing in a localized linear epidermal nevus. Cutis 1980;25: 295-297, 299.

15 Adamson HG: On the nature of rodent ulcer: its relationship to epithelioma adenoides cysticum of Brooke and to other trichoepitheliomata of benign nevoid character; its distinction from malignant carcinoma. Lancet 1914;183:810-814.

Pinkus H: Premalignant fibroepithelial tumors of the skin. Arch Dermatol Syph 1953;67:598-615. Chun K, Vazcuez M, Sanchez JL: Nevus sebaceous: clinical outcome and considerations for prophylactic excision. Int J Dermatol 1995;34:538-541. 


\section{Case Reports in Dermatology}

\begin{tabular}{l|l}
\hline \multicolumn{2}{l}{ Case Rep Dermatol 2015;7:20-24 } \\
\hline DOI: 10.1159/000380846 & $\begin{array}{l}\text { ○ 2015 S. Karger AG, Basel } \\
\text { www.karger.com/cde }\end{array}$ \\
\hline
\end{tabular}

Viana et al.: Basal Cell Carcinoma Arising on a Verrucous Epidermal Nevus: A Case Report

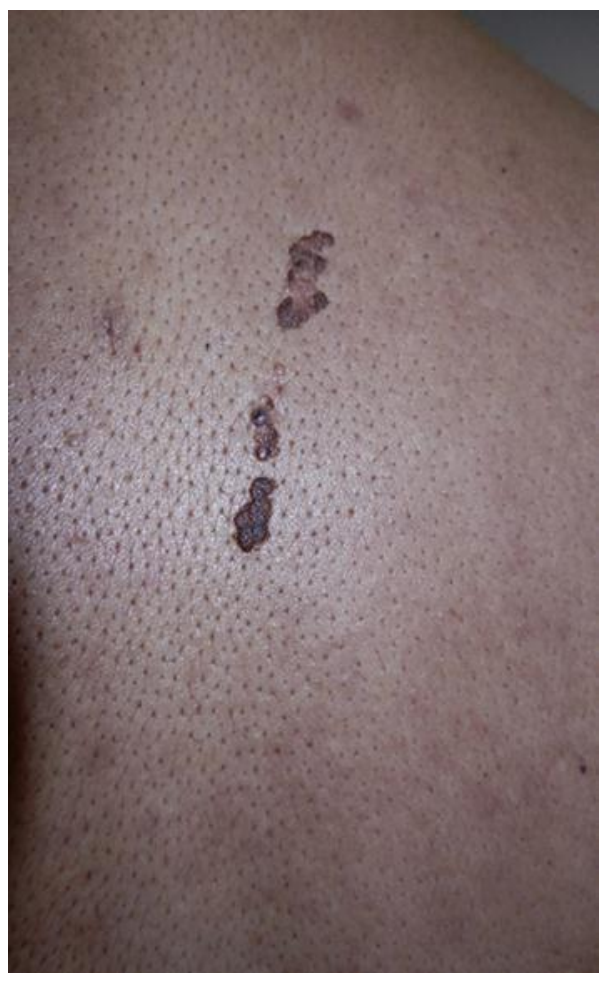

Fig. 1. Verrucous epidermal nevus in the interscapular region, showing a darkened papule with pearly shine in its central portion.

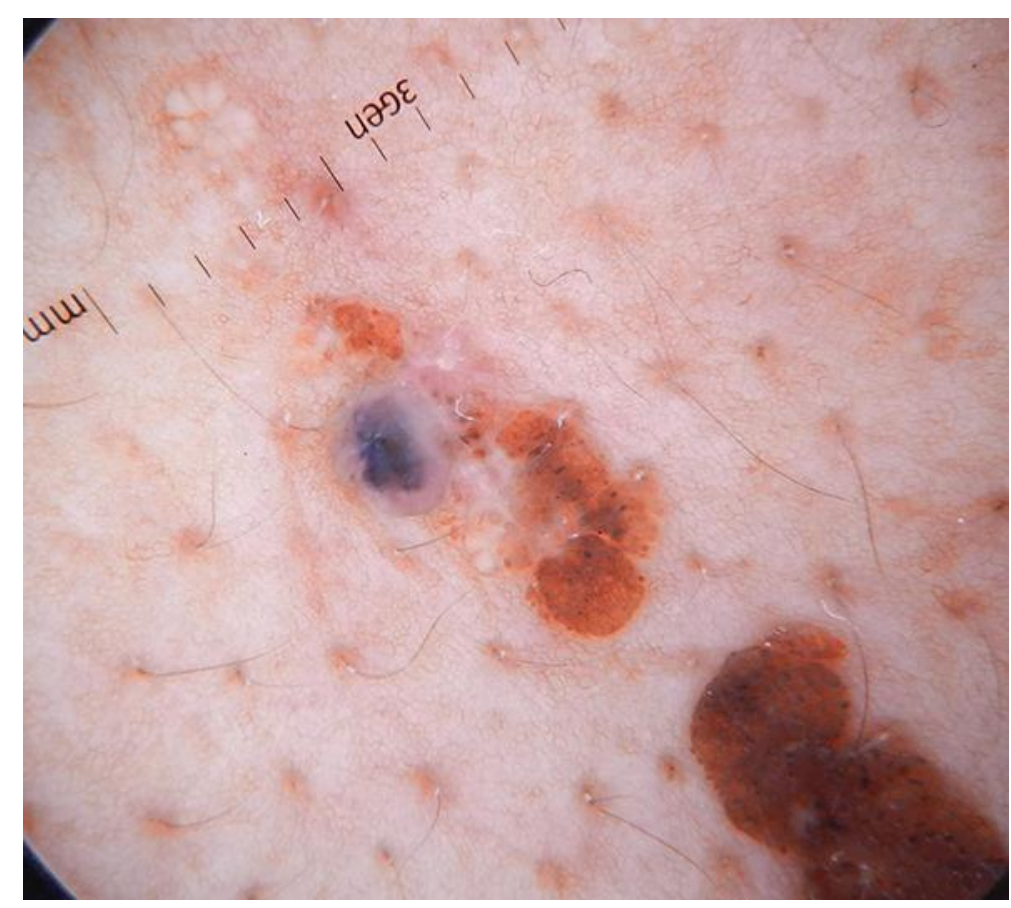

Fig. 2. Dermoscopy showing a cerebriform pattern with follicular pseudo-openings and a large ovoid nest with arboriform vessels $(\times 10)$. 
Viana et al.: Basal Cell Carcinoma Arising on a Verrucous Epidermal Nevus: A Case Report

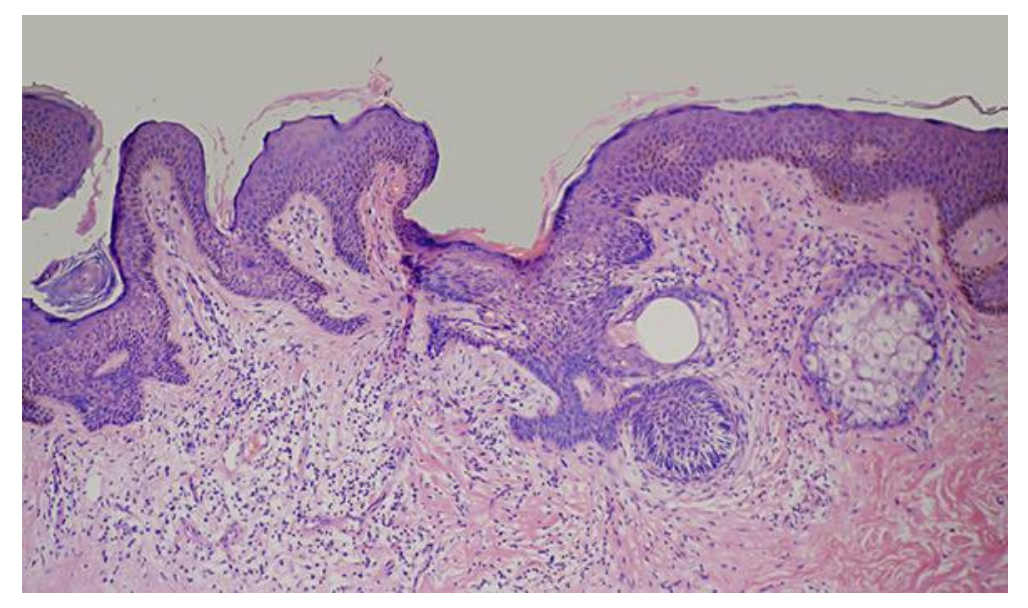

Fig. 3. Histopathology showing epidermis with hyperkeratosis, acanthosis, papillomatosis and clear basal melanic pigment: verrucous epidermal nevus $(\mathrm{HE}, \times 40)$.

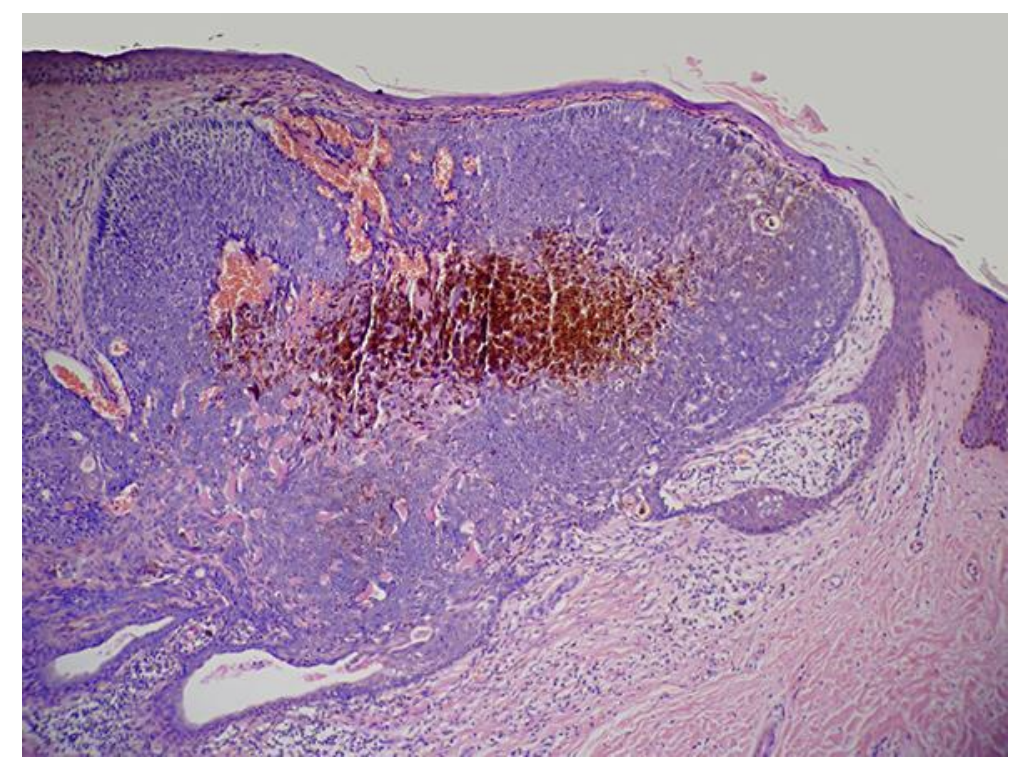

Fig. 4. Histopathology showing thin epidermis over the dermal lesion represented by groupings of basaloid cells with a peripheral nuclear palisade. The center of the tumoral grouping imprisons a melanic pigment and, in its periphery, congested and dilated capillary can be seen, compatible with BCC $(\mathrm{HE}, \times 40)$. 